\title{
PETROLEUM CHEMICALS INDUSTRY IN GREAT BRITAIN
}

$\mathrm{U}$ NDER the joint auspices of the Society of Chemical Industry (London Section) and the Institute of Petroleum, a full day was devoted to a symposium on the "Production and Utilization of Petroleum Raw Materials in the U.K. Chemical Industry", which was hold on March 2 at the Institution of Electrical Engineers, Savoy Place, London. Twelve papers, previously circulated, were briefly outlined by their authors, and discussion followed. The questioning was direct, though an understandable desire of industrial firms to retain their trade secrets led on occasion to reticence in giving equally direct replies. Throughout, the discussion was spirited; the wide range of subjects considered led, not to a diffusion of interest, but to a shaping and crystallization of views that was informative and helpful.

In opening the symposium, Mr. E. J. Dunstan (Manchester Oil Refinery, Ltd.) compared the earlier development of the petroleum chemicals industry in the United States with the growing British effort in this field. The natural conservatism in Britain of old-established industries and the inability of industrial organizations to pay for development projects out of earnings have impeded that growth and proliferation which are essential if the chemical industry is to make an adequate contribution to the well-being of the people and to the balance of trade. After making due allowance for the different economic elimates of the United States and Great Britain and the industrial and commercial requirements and trends peculiar to the latter country which may invalidate arguments based on simple analogy, Mr. Dunstan concluded that the British petroleum chemicals industry requires substantial additional resources of capital, an increased intake of technically trained men (particularly chemical engineers) and the full collaboration of labour; otherwise its energetic beginnings which promised so much may die away, and the opportunities that this young industry offers for strengthening the national economy may well be lost.

This theme of the economic effect of the industry on our trading position was elaborated by Dr. R. F Goldstein (British Oxygen Co., Ltd.). The chemical industry as a whole has increased its production capacity since 1948 from $£ 327$ to nearly $£ 500$ millionan increase which compares very favourably with the expansion-rate of other industries in Great Britain and with that of the chemical industry in other European countries. To this increase, the petroleum chemicals industry has made a substantial contribution, at the cost of capital investment in the region of $£ 40-50$ million. If the British industry were to continue to grow at the same proportionate rate as the United States petroleum chemicals industry is expected to develop, according to the Paley Report, during the next twenty-five years, then additional capital investment at the rate of $£ 14$ million a year would be required, and the whole chemical industry would demand about $£ 70$ million a year for comparable expansion. The threat of capital starvation of the industry is real, and the hope of survival lies in the probability that the profit record of the chemical industry as a whole will prove a sufficiently strong attraction to new risk capital.

The technical basis of the industry was outlined by Dr. H. K. Whalley (British Industrial Solvents,
Ltd.). Oil refining offers a range of raw materials extending from methane (which may be used for the production of synthesis gas, acetylene, hydrocyanic acid, etc.), ethylene, ethane, $C_{3} s$ and $C_{4} s$, to the light distillates such as naphtha, kerosine and gas oil, which are the feed stocks for cracking processes specially developed for making olefines and aromatics for subsequent chemical conversion. Oil-refining processes such as thermal and catalytic reforming and thermal and catalytic cracking, which are designed primarily to give increased quantities of high-quality gasoline, also yield gases as by-products which serve as starting materials for the petroleum chemicals industry. Further, catalytic reforming processes developed by the oil industry for the octane-number improvement of gasoline and naphtha may be adapted for aromatics production. The conventional oil-refining industry is therefore making a dual contribution to the development of petroleum chemicals: it provides the charge stocks from which the essential olefines and aromatics may be made, and it aids the technological growth of the new industry by its own research, development and experience in eracking, alkylation, reforming and polymerization processes. These ties between petroleum refining and petroleum chemicals production are not restrictive: mutual benefits, both technical and economic, must come from the closest association of the two industries.

Two aspects of plant design and construction were dealt with by Mr. E. Smith (Firth-Vickers Stainless Steels, Ltd.) and Mr. E. O. Curtiss (The Lummus Co., Ltd.). The dangers of intergranular corrosion of unstabilized 18/8 austenitic steels, due to deposition of chromium carbide at grain boundaries, was strongly emphasized. Ordinary $18 / 8$ steel, when reheated to $500-800^{\circ} \mathrm{C}$., is rendered susceptible to this defect, but the risk can be eliminated if titanium or niobium is added to the steel. Though full details of a wide range of corrosion- and heat-resisting steels were given, Mr. Smith stressed the desirability of designers, fabricators and users consulting with steel manufacturers, so that the needs of each particular job could be more satisfactorily met.

Some problems in the design of plants for the recovery of light olefines from refinery and cracker gases were described by Mr. Curtiss, with emphasis on the absorption-fractionation method. The preliminary removal of sulphur and acetylene, followed by drying of the gas stream, was outlined, and the design and operation of the absorption-fractionation system were described in detail. The alternative process relying on low-temperature distillation and cascade refrigeration systems was also discussed, and the point was made that the relative merits of the two processes are dependent upon the nature of the feed stock and the required recoveries and purities of the product gas streams. In discussion, Mr. Curtiss observed that the hypersorption process, which relies upon the adsorption of gases by charcoal and their selective desorption, is less widely used, and the reason may lie in the difficulties in stripping the adsorbent and in its attrition.

The synthesis of ethyl alcohol by the catalytic hydration of ethylene at the Grangemouth factory of British Petroleum Chemicals, Ltd., is an outstanding manifestation of two of the major lines of 
the petroleum chemicals industry, which were well recognized by the symposium. The first is the tendency of the industry to offer an alternative route to chemicals previously made from vegetable products, and the second is the application of catalytic methods which dispense with the need for heavy inorganic chemicals that contribute no essential ingredient to the finished compound. The cost of producing alcohol by fermentation of molasses is dependent largely on the price of molasses, which is itself dependent upon world sugar production, cattle feed requirements (particularly in the United States) and the varying demand for industrial alcohol. So influential have these and other factors been that, during the past twenty years, the price of Cuban molasses has ranged from $£ 310 s$. to $£ 25$ a ton. By basing the production of ethyl alcohol on petroleumderived ethylene, it is confidently expected that a more stable price-structure, and one set at an economically lower level, will result. In the United States, half of the industrial alcohol produced is synthetic alcohol. The decision having been made to adopt petroleum as the base for alcohol manufacture, a choice had to be made between the two methods available, namely, by the well-established process of absorbing the ethylene in sulphuric acid to obtain the ethyl esters which are afterwards hydrolysed, or by the Shell method of hydrating ethylene directly, phosphoric acid on 'Celite' (a diatomaceous earth) being used as the catalyst. Mr. A. J. Johnson, presenting the paper prepared by $\mathrm{Mr}$. C. R. Nelson and himself (Shell Development Co.), described this second and preferred course which eliminates the problems involved in the use of sulphuric acid, including those of reconcentration of the acid, disposal of impure acid, and corrosion effects. The direct hydration of ethylene is conducted at about 1,000 lb./sq. in. gauge and $300^{\circ} \mathrm{C}$.; the molar ratio water/ethylene is $0 \cdot 6$, and the conversion of ethylene per pass is low (about 4 per cent). The choice of these reactor conditions is largely determined by economic considerations.

Two other instances of new processes, which avoid the use of substantial quantities of inorganic chemicals, were the subject of papers. The economies of the catalytic direct oxidation of ethylene by air over a silver catalyst to yield ethylene oxide, in contrast to the older chlorhydrin process which consumes large amounts of chlorine and lime (about two tons of each per ton of ethylene oxide made), were presented by Dr. E. T. Borrows and Mr. D. A. Caplin (Petrochemicals, Ltd.). On the basis of conservative estimates of capital costs and yields, the direct oxidation process shows significant advantages, particularly under competitive market conditions, which may be expected to force down the selling price of ethylene oxide. The meeting showed a lively interest in the technical aspects of the process, which the economic calculations tacitly assumed, and questions were put on the patent position, the catalysts used, the need for moderators to suppress 'hot spot' formation, the tolerable acetylene concentration in the feed gas, and the carbon monoxide in the recycle. Published data on these points are, however, scanty, and those members of the meeting who may have been in a position to contribute information on these matters withheld their views. The strong attitude of caution in accepting the claimed merits of the direct oxidation process might be dispelled if at least some of the data from existing plants in the United States were made available and if performance reports on the plants at present under construction in the United States and on the Continent of Europe, couched in something better than meaningless general terms, could, in due course, be released. Though it would be foolish to expect trade secrets to be given away, the paucity of performance data prevents impartial assessment, and retards, by some years, the more widespread adoption of a process that may well be as good as the, paper economics imply.

Mr. F. E. Salt (The Distillers Co., Ltd.) provided the third example of an elegant process which dispenses with the use of heavy inorganic intermediates. The well-established methods for synthesizing phenol from benzene rely upon using sulphuric acid or chlorine as basic raw materials, and involve corrosive conditions. The new process developed by the Distillers Co. and the Hercules Powder Co. converts benzene and propylene, via isopropyl benzene, to phenol and acetone. Its advantages have been judged to warrant the construction of a number of plants overseas which are expected to come into production soon. The essential basis of the process-that is, alkylation, followed by oxidation to the hydroperoxide and its decomposition to the corresponding phenol and ketone-is of wide applicability; for example, sec.-butyl benzene yields phenol and ethyl methyl ketone; $m$ - and $p$-diisopropyl benzenes yield acetone with resorcinol and quinol, respectively. The capital cost of a plant to produce 10,000 tons phenol a year and 6,000 tons acetone a year is estimated to be $£ 1.75$ million, which is slightly less than that required for phenol plants of the same capacity employing older processes. Further, if reasonable values (for example, 1952 price-levels) are taken for raw materials, utilities, labour and for the acetone credit, then the cost of production of phenol by this route is about 70-80 per cent of that by any of the other routes.

An outline of the production of polystyrene and its utilization in a variety of industries, as presented by Dr. V. G. Bashford and Mr. S. D. Eagleton (Monsanto Chemicals, Ltd.), raised questions relating to the use of methyl styrene. It appears that the use of methyl styrene offers the possibility of more rapid polymerization, and though the polymers are less suitable for injection moulding, they promise well for incorporation in surface coatings. The advantages of toughened polystyrene in comparison, say, with toughened polyvinyl chloride were discussed, and doubt was expressed as to the ability of the product to retain over periods of three to four years the high impact strength and improved elongation that the freshly prepared material possesses.

The paper by Mr. W. G. Oakes and Mr. H. C. Raine (Imperial Chemical Industries, Ltd.) on polythene was of outstanding merit in demonstrating the best features of the scientific approach in carrying a project through research and development to fullscale production, followed by the subsequent elaboration of the first direct course, so that a wider range of products of desired and predictable properties may be made. The fundamentals of polythene formation have been carefully examined, and many techniques and approaches have been used to elucidate the polymerization process and the structure and nature of the product. At first believed to be a straight-chain polymer, polythene is now known to be made up of molecular chains that are branched. The application of X-ray diffraction, infra-red spectrographic analysis, studies of osmotic pressure 
and viscosity of solutions, light scattering and other techniques have contributed to the present conception of the structure of polythene, but even now it is not fully resolved. Each finite sample of polythene is made up of molecules having quite a wide spread of molecular weight. The physical properties of the polymer depend upon both the chemical features and also on the arrangement of the molecules in relation to one another in the solid state. Polythene is partly crystalline: in the commercial material, probably about 70 per cent of the molecules are in the ordered state. The authors of this paper correlated chemical and structural features with electrical conductivity, melt viscosity, melt elasticity, softening point and mechanical and physical properties in the solid state. A point of interest which the discussion evoked was that, under the action of gamma-rays, cross-linking is caused, resulting in the transformation of polythene to a glassy, brittle solid. This effect is similar to that produced by a very prolonged photo-oxidation; the mechanism of the change is a matter for speculation.

A second paper from Imperial Chemical Industries, Ltd., on butane dehydrogenation, by Mr. E. Beesley and Dr. B. Whipp, was equally creditable as a record of the rapid development, in collaboration with Universal Oil Products, ltd., of a process under the stress of war-time conditions of emergency and improvisation. A mixture of iso and normal butanes (usually 70 per cent iso) was dehydrogenated over an alkali-promoted chromia-alumina catalyst to the corresponding butenes. This essential step in the production of isooctane for aviation gasoline was brought to successful operation; one major difficulty, namely, the random choking of the reaction tubes due to excessive and unpredictable coke formation, was cured by introducing $30-40$ p.p.m. carbon disulphide in the charge. The carbon disulphide was thought to passivate the tube material against alternate oxidation and reduction, thus preventing the catalysis of carbon formation by finely divided metal. In the discussion, it was said that the process is now in operation for the production of isobutene from isobutane in an integrated plant, wherein this step fits in with other industrial processes.

The separation and utilization of $\mathrm{C}_{4}$ olefines, which are becoming increasingly available from the new oil refineries and petroleum chemicals cracking-plants, was reviewed by Dr. E. T. Borrows and Mr. W. L. Seddon (Petrochemicals, Ltd.). It is of particular interest that whereas the $\mathrm{C}_{4}$ stream from oil-refinery catalytic crackers contains virtually no butadiene, the plants installed by petroleum ehemicals works for the cracking of naphtha, gas oil, etc., yield a $\mathrm{C}_{4}$ stream containing substantial amounts of butadiene. This constitutes both an opportunity and a problem. Considerable interest was shown in the authors' suggestion that, from a mixed $\mathrm{C}_{4}$ stream containing butadiene, the isobutene may first be removed by selective absorption in sulphuric acid without absorbing appreciable amounts of the butadiene present; in fact, more than 90 per cent of the butadiene may be afterwards recovered.

The series of specialist papers was concluded by the paper by Dr. D. P. Dodgson (Monsanto Chemicals, Ltd.) on the use of additives based on petroleum for improving the quality of various petroleum fractions. A wide range of products, including chlorinated waxes, sulphonation products, naphthenic acids, viscosity index improvers, pourpoint depressants, etc., were dealt with. In the discussion, interest was shown in the use of additives to give oils of both high- and low-viscosity indices, and in the liability of viscosity index improvers to break down at high rates of shear. Dr. Dodgson gave the assurance that conventional lubricating oils containing additives from different manufacturers are, in general, mutually compatible.

Sir Robert Robinson, in the closing address, pointed out that the world chemical industry is highly competitive, and, if the British complement is to survive, it must keep in the race : any early financial losses in establishing the petroleum chemicals industry must be accepted; national and strategic interests make it imperative that the necessary capital to sustain development and growth of the industry must be found. The symposium, he said, rightly laid stress on an essential theme of this new industry : that is, its facility for developing alternative processes which do not require the use of substantial quantities of heavy inorganic chemicals, for example, in the production of acetone and phenol by the Distillers Co., Ltd., process, and of ethylene oxide by the catalytic oxidation of ethylene. This theme should be vigorously developed. Research over a broad front on catalysis should be conducted, and in this attack, continued Sir Robert, government departments such as the Chemical Research Laboratory and the Fuel Research Station of the Department of Scientific and Industrial Research should play an outstanding part. Recent research has demonstrated that there are many reactions and processes which hold high promise of industrial exploitation in Britain : the Fischer-Tropsch reaction and the Oxo syntheses are well-known examples. The recent work of Ziegler on the use of lithium and aluminium hydrides as catalysts in controlled polymerization processes may also lead to economic routes to both known and new products. These are only examples of the many opportunities, some known, some awaiting discovery, that lie before us, and only by our own energy and unsparing effort can they be won.

\section{CLAY - WATER RELATIONSHIPS}

A MEETING of the Clay Minerals Group of the Mineralogical Society, held at the laboratories of the British Ceramic Research Association, Stokeon-Trent, during November 7-8 last, was devoted to a discussion upon clay - water relationships. The meeting was preceded, on the morning of November 7 , by a visit to the laboratories of the Association. At the scientific sessions the chair was taken on the afternoon of November 7 by Dr. G. W. Brindley (University of Leeds), and on the morning of the following day by Dr. G. Nagelschmidt (Safety in Mines Establishment, Sheffield).

The discussion was opened by a review of the significance of clay - water relationships in ceramics by D. A. Holdridge and F. Moore (British Ceramic Research Association). Plasticity and strength data as well as the Pfefferkorn and modified Pfefferkorn numbers for ball and china clays were related to dehydration data, and discussed in relation to the concept of 'planar' and 'broken-bond' water; the former is removed below $110^{\circ} \mathrm{C}$., but removal of the latter is incomplete below about $250-275^{\circ} \mathrm{C}$. In describing the rheological properties of importance 